\title{
Long-term extracorporeal membrane oxygenation after severe blunt traumatic lung injury in a child
}

\author{
Ok Jeong Lee', Yang Hyun Cho ${ }^{2}$, Jinwook Hwang ${ }^{3}$, Inae Yoon', Young-Ho Kim', Joongbum Cho ${ }^{4}$ \\ 'Department of Pediatrics, Gyeongsang National University Changwon Hospital, Gyeongsang National University College of Medicine, Changwon; \\ ${ }^{2}$ Department of Thoracic and Cardiovascular Surgery, Samsung Medical Center, Sungkyunkwan University School of Medicine, Seoul; ${ }^{3}$ Department of \\ Thoracic and Cardiovascular Surgery, Korea University Ansan Hospital, Korea University College of Medicine, Ansan; ${ }^{4}$ Department of Critical Care Medicine, \\ Samsung Medical Center, Sungkyunkwan University School of Medicine, Seoul, Korea
}

Managing acute respiratory distress syndrome (ARDS) after severe blunt traumatic lung injury can be challenging. In cases where patients are refractory to conventional therapy, extracorporeal membrane oxygenation (ECMO) should be considered. In addition, the heparin-coated circuit can reduce hemorrhagic complications in patients with multiple traumas. Although prolonged ECMO may be necessary, excellent outcomes are frequently associated. In this study, we report long-term support with venovenous-ECMO applied in a child with severe blunt trauma in Korea. This 10-year-old and 30-kg male with severe blunt thoracic trauma after a car accident developed severe ARDS a few days later, and ECMO was administered for 33 days. Because of pulmonary hemorrhage during ECMO support, heparin was stopped for 3 days and then restarted. He was weaned from ECMO successfully and has been able to run without difficulty for the 2 years since discharge.

Key Words: acute respiratory distress syndrome; extracorporeal membrane oxygenation; pediatrics; thoracic injuries

Blunt thoracic injury is common in motor vehicle accidents and has a high mortality rate that accounts for $26 \%$ of deaths in children [1]. This can also result in acute respiratory distress syndrome (ARDS), which can be challenging to manage. Depending on the severity, mortality in these cases can be up to $30 \%-45 \%[2,3]$. When a patient does not respond to conventional therapy, such as lung-protective mechanical ventilation, extracorporeal membrane oxygenation (ECMO) can be applied as a treatment option; its use has recently increased in patients with ARDS [4].

However, in cases of ARDS after traumatic injury, patients are at a high risk of severe bleeding during ECMO support because of systemic anticoagulation. The risk of hemorrhagic complications such as intracranial hemorrhage as well as surgical and cannular site bleeding is $40 \%$ in patients treated with venovenous (VV)-ECMO. Patients with recent major trauma and those undergoing damage-control interventions may have trauma-induced coagulopathy and higher bleeding risk [4]. ECMO has recently been used for patients with multiple traumas because it can reduce hemorrhagic complications with the development of ECMO technology and the application of a heparin-coated circuit [5].

\section{Case Report}

Received: May 23, 2016

Revised: October 8, 2016

Accepted: October 10, 2016

Corresponding author

Joongbum Cho

Department of Critical Care

Medicine, Samsung Medical Center,

Sungkyunkwan University School of

Medicine, 81 Irwon-ro, Gangnam-

gu, Seoul 06351, Korea

Tel: +82-2-3410-3699

Fax: +82-2-2148-7088

E-mail: joongbum.cho@gmail.com

Copyright () 2019 The Korean Society of Critical Care Medicine

This is an Open Access article distributed under the terms of Creative Attributions Non-Commercial License (http:// creativecommons.org/li-censes/by-nc/4.0/) which permits unrestricted noncommercial use, distribution, and reproduction in any medium, provided the original work is properly cited. 
Prolonged use of ECMO ( $>14$ days) has been applied for respiratory failure and is associated with an increase in survival rates as high as $50 \%-70 \%$ to native lung recovery [6]. In this study, we discuss the case of a pediatric patient who recovered respiratory function after long-term use of VV-ECMO following a blunt crushing traumatic lung injury due to a traffic accident.

\section{CASE REPORT}

A 10-year-old, 30-kg male had severe blunt thoracic trauma after he was hit and his chest was run over by a car. On admission to the emergency room, he was alert but cyanotic $\left(\mathrm{SpO}_{2}\right.$ $58 \%$ ) and dyspneic. His initial vital signs were blood pressure of 147/111 mm Hg, heart rate of 160 beats/min, respiratory rate (RR) of 40 breaths $/ \mathrm{min}$, and a body temperature of $36^{\circ} \mathrm{C}$. Initial arterial blood gas analysis revealed the following results: $\mathrm{pH}$ 7.167, $\mathrm{PaCO}_{2}$ (partial pressure of carbon dioxide in arterial blood) $55.6 \mathrm{~mm} \mathrm{Hg}, \mathrm{PaO}_{2}$ (partial pressure of oxygen in arterial blood) $40.3 \mathrm{~mm} \mathrm{Hg}$, and $\mathrm{HCO}_{3}{ }^{-} 18.7 \mathrm{mmol} / \mathrm{L}$. Endotracheal bleeding was observed during intubation and mechanical ventilation was started. A bilateral closed thoracostomy was performed due to bilateral pneumothorax (Figure 1A and B). Extensive lung contusion of both lungs with a hemothorax, pneumothorax, pneumomediastinum, and fracture in the right first rib were indicated on chest computed tomography (Figure 1C). He showed ARDS based on $\mathrm{PaO}_{2} / \mathrm{FiO}_{2}$ (fraction of inspired oxygen) 62 . There was no injury on the head and neck, cardiovascular system or abdominal organs. His initial injury severity score was 25 and lung injury score was 15. His lung condition started to deteriorate on hospital day 9. Hypoxemia was not improved, with $\mathrm{PaO}_{2} / \mathrm{FiO}_{2}<100$ in spite of $10 \mathrm{~mm} \mathrm{Hg}$ of positive end-expiratory pressure (PEEP) and $100 \%$ of $\mathrm{FiO}_{2}$. V-ECMO was applied on hospital day 11 because oxygenation could not be maintained as $\mathrm{PaO}_{2} / \mathrm{FiO}_{2} 99$ despite $12 \mathrm{~cm}$

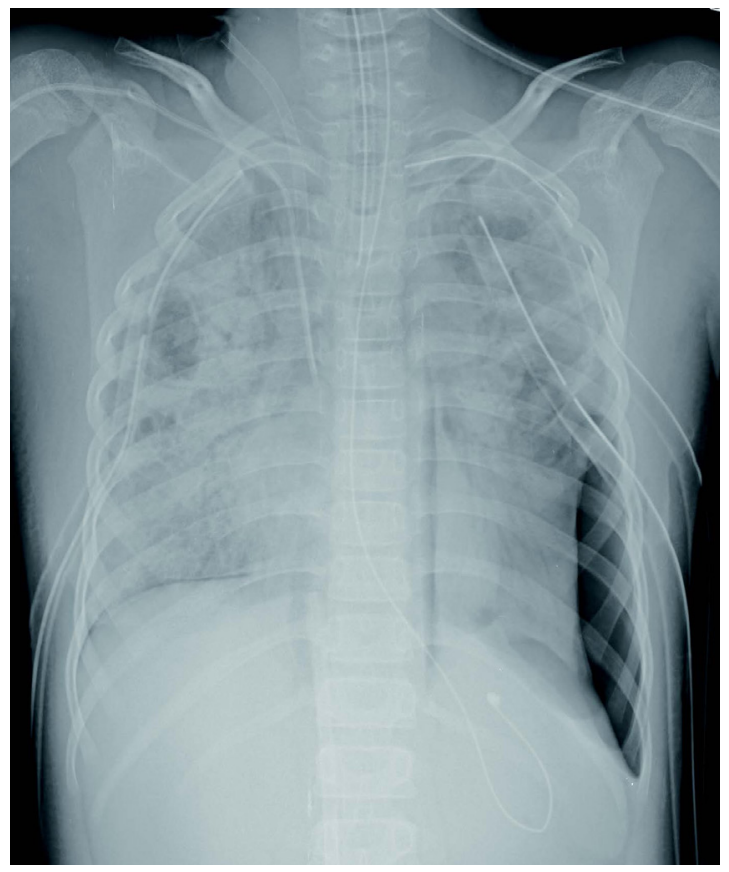

Figure 2. Chest radiograph on day 0 of extracorporeal membrane oxygenation.
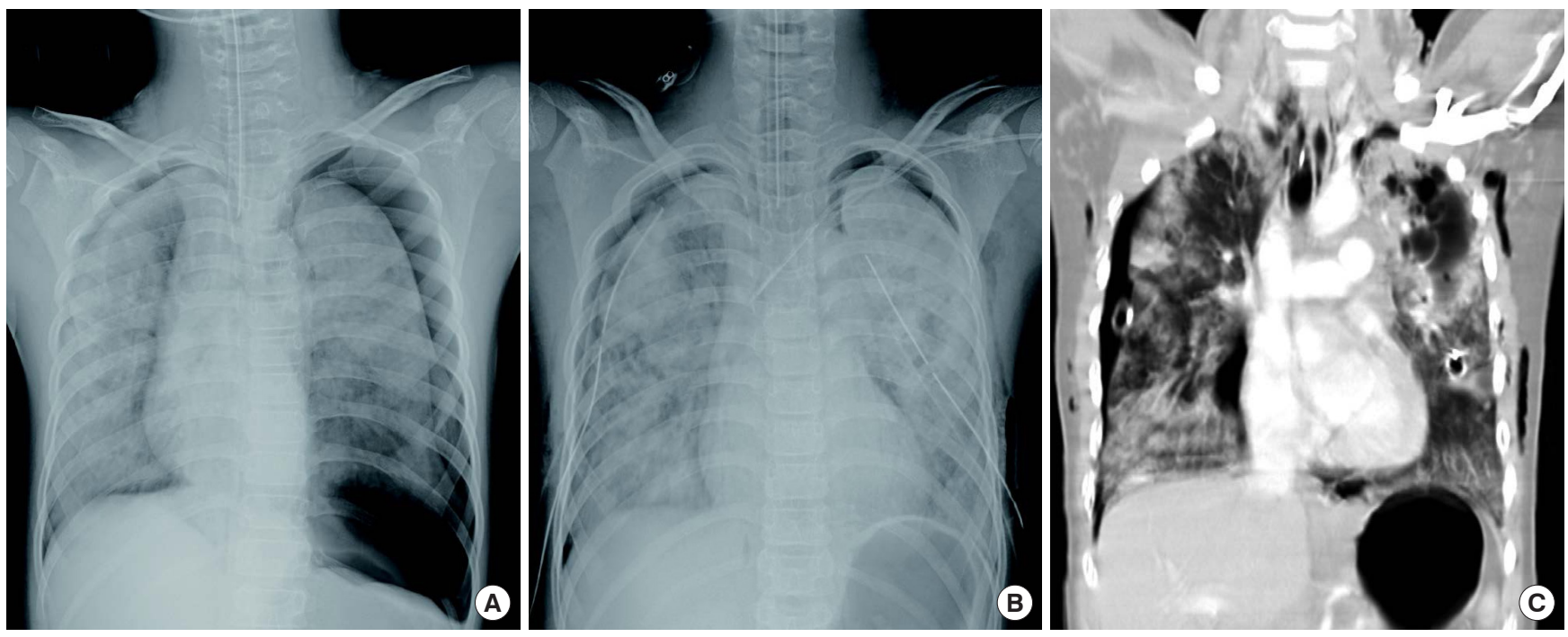

Figure 1. A Chest radiograph on admission: (A) bilateral pneumothorax and pneumomediastinum, and (B) after bilateral closed thoracotomy. (C) Chest computed tomography on the day of admission. Extensive lung contusion of both lungs with left hemothorax, right pneumothorax, and pneumomediastinum. 
$\mathrm{H}_{2} \mathrm{O}$ PEEP (Figure 2). Oxygen Index was 18.2 right before ECMO implantation. High frequency of ventilator could not be applied because it was not available. For implantation of ECMO, vessel cannulation was performed with a 14-Fr Edward cannula in the left femoral vein and 14-Fr Biomedicus cannula in the right femoral vein. However, recirculation occurred right after ECMO support. A 14-Fr Edward arterial cannula was added in right internal jugular vein and then both femoral vein cannulas were used as drainage and the right jugular vein cannula was used as the return. A Maquet oxygenator was used for ECMO and blood flow was 3,300 ml/min, 1,940 revolutions per minute (rpm), with sweep gas $2 \mathrm{~L} / \mathrm{min}$ (body surface area $0.68 \mathrm{~kg} / \mathrm{m}^{2}$ ). Heparin was started with 150-160 seconds of activated clotting time (ACT). Thoracoscopic left lung repair and bleeding control were performed on VV-ECMO support. However, his pulmonary hemorrhage continued and his lung condition deteriorated to only $2.5 \mathrm{ml} / \mathrm{kg}$ of tidal volume (TV) with peak inspiratory pressure (PIP) $28 \mathrm{~cm} \mathrm{H}_{2} \mathrm{O}$. On day 7 of ECMO, the patient was transferred to a tertiary hospital. At the time of transfer, ECMO blood flow was 3,100 $\mathrm{ml} / \mathrm{min}(2,120 \mathrm{rpm}$, sweep gas $4 \mathrm{~L} / \mathrm{min})$ and the ventilator setting was synchronized intermittent mandatory ventilation (SIMV) with pressure support (PS) mode (PS $13 \mathrm{~cm} \mathrm{H}_{2} \mathrm{O}$ ), $\mathrm{FiO}_{2}$ 0.3, PEEP $12 \mathrm{~cm} \mathrm{H}_{2} \mathrm{O}$, TV $100 \mathrm{ml}(3.4 \mathrm{ml} / \mathrm{kg})$ and RR of 25 breaths/ min. After transfer, heparin was stopped for 3 days because of pulmonary hemorrhage and red blood cells were transfused to the patient. The ventilator was set at pressure control mode, $\mathrm{FiO}_{2}$ 0.4, PEEP $8 \mathrm{~cm} \mathrm{H} \mathrm{H}_{2} \mathrm{O}$, PIP $23 \mathrm{~cm} \mathrm{H}_{2} \mathrm{O}$, RR 20 breaths/min, and TV $75 \mathrm{ml}(2.6 \mathrm{ml} / \mathrm{kg})$. Heparin was restarted at a dosage of $10 \mathrm{U} / \mathrm{kg} / \mathrm{hr}$ and then titrated with a target ACT of 150-180 seconds. No further pulmonary hemorrhage was observed. With physiotherapy including prone positioning and infection control for ventilator-associated pneumonia, the patient's TV was increased to $4.5 \mathrm{ml} / \mathrm{kg}$ with a ventilator setting at SIMV and PS mode, PEEP $6 \mathrm{~cm} \mathrm{H}_{2} \mathrm{O}$, PIP $24 \mathrm{~cm} \mathrm{H}_{2} \mathrm{O}$, and RR 20 breaths/ min on day 20 of ECMO. On day 29 of VVECMO, the TV was increased to $7 \mathrm{ml} / \mathrm{kg}$ in the SIMV and PS mode, with the lower PEEP and PIP at $5 \mathrm{~cm} \mathrm{H}_{2} \mathrm{O}$ and $20 \mathrm{~cm} \mathrm{H}_{2} \mathrm{O}$, and $\mathrm{RR} 20$ breaths/ min. VV-ECMO was removed on day 33 of ECMO application. There were no complications related to ECMO cannulation except recirculation on initial ECMO support. Mechanical ventilation was weaned 6 days after ECMO removal. The patient was able to walk and was discharged 23 days after ECMO removal (hospital day 68) (Figure 3). Two years after the event, the patient was able to run without difficulty and had a mild restrictive pulmonary function test pattern, with a $62 \%$ forced vital capacity, $60 \%$ forced expiratory volume in 1 second, forced

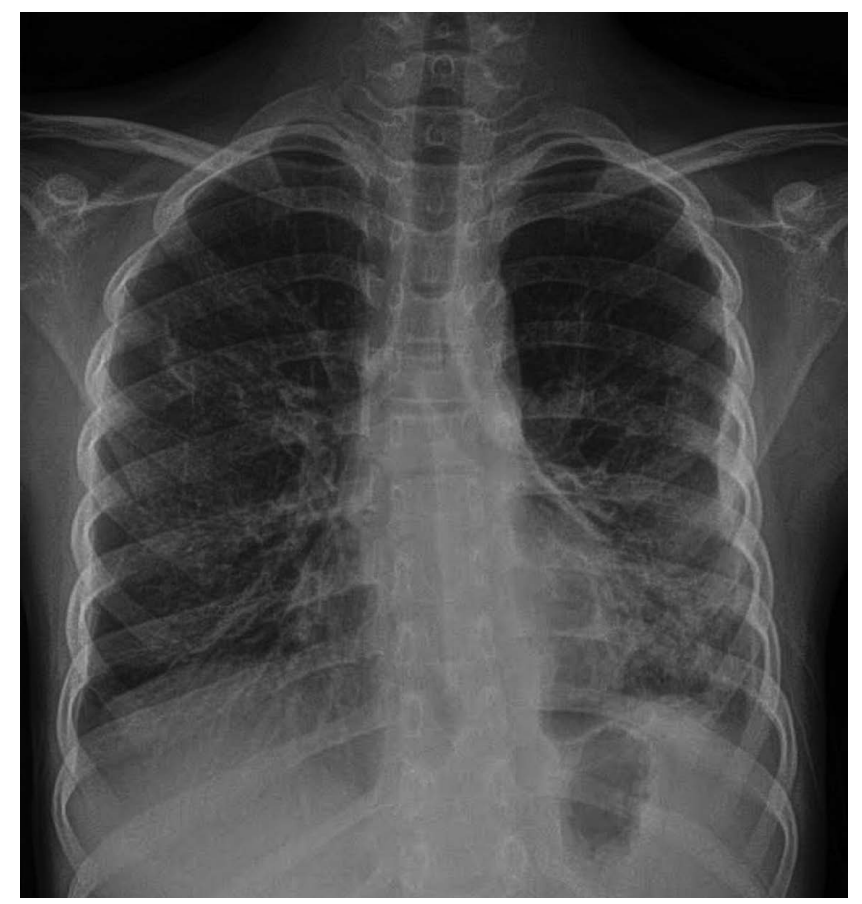

Figure 3. Chest radiograph 23 days after extracorporeal membrane oxygenation removal.

expiratory flow (FEF) $25 \%-75 \%$ of $73 \%$, FEF $50 \%$ of $107 \%$, and a peak expiratory flow of $94 \%$.

\section{DISCUSSION}

High impact traumas, such as motor vehicle or car accidents, are common causes of thoracic injuries in children [1]. Complications that follow severe trauma, such as ARDS, are associated with high mortality, with rates as high as $30 \%-45 \%$, particularly in fulminant ARDS [2,3]. Managing ARDS after severe chest trauma remains a challenge. Patients with ARDS often require a prolonged stay in the intensive care unit and cases refractory to conventional therapy may require ECMO support [5].

ECMO is an intensive treatment that is used to support patients with respiratory or cardiac failure who are unresponsive to conventional therapy [2]. Because neonatal ECMO was associated with $81 \%$ survival rates $(n=715)$ when administered for respiratory failure in the 1980s [7], ECMO has been incorporated in adult patient therapy. A retrospective case review of the Extracorporeal Life Support Organization registry from 1986 to $2006(n=1,473)$ reported 50\% survival to discharge of adult ECMO respiratory failure patients [8]. ECMO has currently become the standard treatment for cardiac and pulmonary failure that is unresponsive to other management in all 
age groups.

However, patients with ARDS after traumatic injury have high risk of severe bleeding related with systemic anticoagulation during treatment. Dismal outcomes are reported in multitrauma patients who undergo emergency cardiopulmonary bypass because of uncontrollable bleeding from systemic heparinization [9]. Therefore, trauma injury was considered a contraindication for ECMO patients until the early 1990's.

ECMO had been administered in patients with trauma injury since the 1990s $[10,11]$ and has recently been used in patients with multiple traumas because of the reduction in hemorrhagic complications associated with the development of ECMO technology and the heparin-coated circuit [5]. In addition, the use of heparin-free ECMO could overcome the bleeding risk in multiple trauma patients with ECMO support. Some cases of non-heparinized ECMO support have been reported in patients with multiple traumas. Arlt et al. [12] reported the survival of six of 10 poly-traumatic patients with pulmonary or cardiopulmonary failure and hemorrhagic shock after application of initially heparin-free ECMO. After effective treatment of bleeding and signs of shock, low-dose heparin was applied to achieve an activated thromboplastin time (aPTT) of double the normal range or an ACT value above $150 \mathrm{sec}$ onds [12]. Muellenbach et al. [13] reported three successful cases of initially heparin-free VV-ECMO in patients $(16,28$, and 53 years old) with traumatic respiratory failure and severe traumatic brain injury. The heparin-free duration was 1-5 days and then low-dose heparin was started after successful hemorrhagic shock treatment, with a target aPTT of 40 to 50 seconds. The authors observed neither thromboembolic events nor unexpected clot formation in the extracorporeal circuit and oxygenator function was not restricted [13].

Long-term ECMO support was previously thought to be associated with unfavorable outcomes. However, advances in ECMO technology and critical care have allowed for successful long term ECMO support. Swaniker et al. [14] reported a $71 \%$ survival rate when ECMO was applied in 128 pediatric patients with respiratory failure due to pneumonia, ARDS and airway problems. This finding indicates that lung recovery occurs even in patients that receive ECMO for prolonged periods, and that the duration of ECMO does not correlate with survival. The longest ECMO run of 47 days was in a patient who survived with viral pneumonia. Renal failure, the need of inotropics, failure to return to dry weight and the absence of lung compliance improvement are factors associated with decreased survival on ECMO [14]. In pediatric trauma patients, VV-ECMO was used for support for 38 days in a 7-year-old pa- tient with post-traumatic ARDS, and the patient regained a functionally normal lifestyle [15].

In our case, the patient was a 10-year-old male with severe ARDS after blunt chest trauma caused by a car accident. He had extensive lung contusion and was considered to be a highrisk case with a lung injury score of 15 . We started ECMO on hospital day 11 because he did not respond to conventional treatment. Although the patient had pulmonary hemorrhage and ventilator-associated pneumonia, he was weaned successfully from ECMO after stopping heparin for 3 days and administering physiotherapy including prone positioning and infection control for ventilator-associated pneumonia. The total duration of ECMO was 33 days. The patient did not have complications related to ECMO cannulation except recirculation on initial ECMO support. The patient was discharged 23 days after ECMO removal. Two years after the event, he was able to run without difficulty.

Our case reports the successful prolonged use of ECMO in a pediatric patient with severe blunt chest trauma in Korea. The results indicate that excellent outcomes are possible for pediatric patients that are given prolonged, aggressive ECMO treatment over 30 days.

\section{CONFLICT OF INTEREST}

No potential conflict of interest relevant to this article was reported.

\section{ACKNOWLEDGMENTS}

We would like to thank the nurses and extracorporeal membrane oxygenation specialists involved in the care of this patient.

\section{ORCID}

OkJeong Lee https://orcid.org/0000-0001-9234-1424

Yang Hyun Cho https://orcid.org/0000-0003-1685-3641

Jinwook Hwang https://orcid.org/0000-0003-4940-165X

Inae Yoon https://orcid.org/0000-0002-7449-3587

Young-Ho Kim https://orcid.org/0000-0001-7120-8130

Joongbum Cho https://orcid.org/0000-0001-5931-7553

\section{AUTHOR CONTRIBUTIONS}

Conceptualization: OJL, YHC, JC. Data curation: YHC, JH. Visualization: IY, YHK. Writing - original draft: OJL, IY. Writing - 
review \& editing: OJL, JC.

\section{REFERENCES}

1. Peclet MH, Newman KD, Eichelberger MR, Gotschall CS, Garcia VF, Bowman LM. Thoracic trauma in children: an indicator of increased mortality. J Pediatr Surg 1990;25:961-5.

2. Schuerer DJ, Kolovos NS, Boyd KV, Coopersmith CM. Extracorporeal membrane oxygenation: current clinical practice, coding, and reimbursement. Chest 2008;134:179-84.

3. ARDS Definition Task Force, Ranieri VM, Rubenfeld GD, Thompson BT, Ferguson ND, Caldwell E, et al. Acute respiratory distress syndrome: the Berlin Definition. JAMA 2012;307:252633.

4. Wu MY, Lin PJ, Tseng YH, Kao KC, Hsiao HL, Huang CC. Venovenous extracorporeal life support for posttraumatic respiratory distress syndrome in adults: the risk of major hemorrhages. Scand J Trauma Resusc Emerg Med 2014;22:56.

5. Madershahian N, Wittwer T, Strauch J, Franke UF, Wippermann J, Kaluza M, et al. Application of ECMO in multitrauma patients with ARDS as rescue therapy. J Card Surg 2007;22: $180-4$.

6. Wiktor AJ, Haft JW, Bartlett RH, Park PK, Raghavendran K, Napolitano LM. Prolonged VV ECMO (265 Days) for ARDS without technical complications. ASAIO J 2015;61:205-6.

7. Toomasian JM, Snedecor SM, Cornell RG, Cilley RE, Bartlett RH. National experience with extracorporeal membrane oxygenation for newborn respiratory failure: data from 715 cases. ASAIO Trans 1988;34:140-7.
8. Brogan TV, Thiagarajan RR, Rycus PT, Bartlett RH, Bratton SL. Extracorporeal membrane oxygenation in adults with severe respiratory failure: a multi-center database. Intensive Care Med 2009;35:2105-14.

9. Phillips SJ, Zeff RH, Kongtahworn C, Skinner JR, Toon RS, Grignon A, et al. Percutaneous cardiopulmonary bypass: application and indication for use. Ann Thorac Surg 1989;47:121-3.

10. Perchinsky MJ, Long WB, Hill JG, Parsons JA, Bennett JB. Extracorporeal cardiopulmonary life support with heparin-bonded circuitry in the resuscitation of massively injured trauma patients. Am J Surg 1995;169:488-91.

11. Michaels AJ, Schriener RJ, Kolla S, Awad SS, Rich PB, Reickert C, et al. Extracorporeal life support in pulmonary failure after trauma. J Trauma 1999;46:638-45.

12. Arlt M, Philipp A, Voelkel S, Rupprecht L, Mueller T, Hilker M, et al. Extracorporeal membrane oxygenation in severe trauma patients with bleeding shock. Resuscitation 2010;81:804-9.

13. Muellenbach RM, Kredel M, Kunze E, Kranke P, Kuestermann J, Brack A, et al. Prolonged heparin-free extracorporeal membrane oxygenation in multiple injured acute respiratory distress syndrome patients with traumatic brain injury. J Trauma Acute Care Surg 2012;72:1444-7.

14. Swaniker F, Kolla S, Moler F, Custer J, Grams R, Bartlett R, et al. Extracorporeal life support outcome for 128 pediatric patients with respiratory failure. J Pediatr Surg 2000;35:197-202.

15. Fortenberry JD, Meier AH, Pettignano R, Heard M, Chambliss CR, Wulkan M. Extracorporeal life support for posttraumatic acute respiratory distress syndrome at a children's medical center. J Pediatr Surg 2003;38:1221-6. 